\title{
Öğretmen Adaylarının İngilizce Özyeterlik İnançlarının Algılanan Başarıları Üzerindeki Etkisi: Dil Öğrenme Çabasının Aracı Rolü
}

DOI: $10.26466 /$ opus.771847

\author{
Selda Özer* - Fatma Başarır ** \\ * Öğr. Gör. Dr., Nevşehir Hacı Bektaş Veli Üniversitesi, Yabancı Diller Yüksekokulu, \\ Nevşehir/Türkiye \\ E-Posta: sozer@nevsehir.edu.tr \\ ORCID: $\quad$ 0000-0003-2648-9150 \\ ** Öğr. Gör. Dr., Nevşehir Hacı Bektaş Veli Üniversitesi, Yabancı Diller Yüksekokulu, \\ Nevşehir/Türkiye \\ E-Posta: basarirfatma@nevsehir.edu.tr \\ ORCID: $\underline{0000-0001-5855-7993}$
}

\begin{abstract}
Öz
Bu çalışmanın amact, öğretmen adaylarının İngilizce öz-yeterlik inançlarının algılanan başarıları üzerindeki etkisinde dil öğrenme çabasının aracı rolünü analiz etmektir. Araştırmanın katılımcıları, 2018-2019 bahar yarıyllında bir devlet üniversitesinin eğitim fakültesinde öğrenim gören 256 birinci sinıföğ rencisinden oluşmaktadır. Verilerin toplanmasında Yanar ve Bümen (2012) tarafindan geliştirilen İngilizce ile ilgili Öz-yeterlik İnancı Ölçeği ve Karabıyık ve Mirici (2018) tarafından geliştirilen Yabancı Dil Öğrenme Çabası Ölçeği kullanılmıştır. Araştırmada, İngilizce öz-yeterlik inancı, dil öğrenme çabası ve algılanan başarı arasındaki ilişkileri belirlemek için Pearson korelasyon analizi uygulanırken, İngilizce öz-yeterlik inancının algılanan başar üzerindeki etkisinde dil öğrenme çabasının aracı rolünü incelemek için PROCES Macro kullanılmıştır. Elde edilen bulgular, İngilizce öz-yeterlik inancl, dil öğrenme çabası ve algılanan başarı arasında pozitif yönde anlamlı ilişkiler olduğunu ortaya koymuştur. Aracılık etkisi için yapılan analizde ise, İngilizce öz-yeterlik inancının algılan başarı üzerindeki etkisinde dil öğrenme çabasının kısmi aracı rolü istatistiksel açıdan anlamlı bulunmuştur. Araştırmanın sonuçları alanyazın ışığında tartışılarak, dil eğitimcilerine, dil öğretim (eğitim) programları geliştirenlere ve öz-yeterlik, öğrenme çabası ve başarı üzerinde çalı̧̧an araştırmacılara yönelik önerilerde bulunulmuştur.
\end{abstract}

Anahtar Kelimeler: Öğretmen adayları, İngilizce öz-yeterlik inancı, Dil öğrenme çabası, Algılanan başarı 


\title{
The Predictiveness of Prospective Teachers' English Self-Efficacy Beliefs on Their Perceived Success: The Mediating Role of Language Learning Effort
}

\begin{abstract}
The aim of the study is to analyze the mediating role of language learning effort on the effect of English self-efficacy belief on perceived success. The participants consisted of 256 freshmen studying at a faculty of education at a state university in 2018-2019 spring semester. Self-Efficacy Scale for English developed by Yanar and Bümen (2012) and Foreign Language Learning Effort Scale developed by Karabıyık and Mirici (2018) were used in data collection. While Pearson correlation analysis was applied to determine the relationships between English self-efficacy belief, language learning effort and perceived success, PROCESS Macro was used to examine the mediating role of language learning effort in the predictiveness of English self-efficacy belief on perceived success. The findings revealed that there were positive and significant correlations between English self-efficacy belief, language learning effort and perceived success. In the mediation analysis, partial mediating role of the language learning effort in the effect of English self-efficacy belief on perceived success was found statistically significant. The results of the research were discussed in the light of the literature and suggestions were made for language educators, language curriculum developers and researchers working on self-efficacy, learning effort and success.
\end{abstract}

Keywords: Prospective teachers, English self-efficacy belief, Language learning effort, Perceived success 


\section{Giriş}

Son yıllarda ulaşım, haberleşme ve iletişim teknolojileri alanlarında meydana gelen hızlı ve baş döndürücü gelişmeler çok hızlı toplumsal dönüşümleri ve uluslararası ilişkilerin giderek artmasını beraberinde getirmiştir. Bu hızı dönüşüm ve artan ilişkiler nedeniyle, toplumlar giderek daha fazla örtüşen ve hatta ülkelerin sınırlarını aşan faaliyetlerde bulunmaktadırlar. Gittikçe artan bu uluslararası ilişkiler sonucu oluşan rekabet, ulusların kendi ana dilleri ile iletişim sağlamalarını yetersiz kılmakta, dolayısıyla diğer ülkelerin dillerini öğrenme gereksinimi ortaya çıkarmaktadır.

Sınırların kalktığı, rekabetin hızlandığı ve iletişim araçlarıyla herkese ve her yere anında ulaşılabilen bu dünyada yabancı dil öğrenmenin gerekliliği açıktır. Globalleşen bu dünyada hızlı bilgi dolaşımının içinde kaybolmamak ve gelişmeleri izleyebilmek için en az bir yabancı dil bilme önem kazanmaktadır (Gömleksiz, 2002). Yabancı dil bilgisinin bireylere iyi bir iş bulma ve sürdürme, farklı kültürlere açık olma, daha kolay ve rahat seyahat etme konusunda güven kazanma, küresel bir anlayışa sahip olma, sosyal ilişkilerini geliştirebilme ve bir çağdaşlık göstergesi olma gibi konularda katkı sağladığı da bilinmektedir (Memduhoğlu ve Kozikoğlu, 2015; Özer ve Korkmaz, 2016, Tekin Özel, 2019). Küreselleşmenin etkileri ve sunduğu bu avantajlar ile birlikte, Türkiye'de yabancı dil öğrenimi/öğretimi, üzerinde önemle durulan bir alan haline gelmiştir. Bu nedenle, yabancı dil dersleri ilkokul ikinci sınıftan yükseköğretime kadar eğitim programlarında zorunlu bir ders olarak yer almaktadır. Ne var ki, harcanan emek, zaman ve para ile kıyaslandığında, yabancı dil öğretiminde ülke genelinde istenilen başarıya ulaşılamadığı gözlenmektedir (Aydın ve Zengin, 2008; Genç, 2016; Memduhoğlu ve Kozikoğlu, 2015).

Elliot (2007) akademik performansi etkileyen ve ona aracılık eden faktörlerin anlaşılmasının güç olduğunu, Arratibel (2013) aynı eğitim süresi boyunca yabancı dil eğitimi alan öğrencilerin farklı derecelerde dil yeterliğine ulaşmalarının araştırmaya değer göründüğünü, Littlewood (2001) ise öğrenenlerin bireysel farklılıklarının dil öğrenme sürecine yansımasının yabancı dil öğrenmeyi karmaşık ve problemli hale getiren unsurlardan birisi olduğunu savunmuştur. Nitekim yapılan araştırmalar, öğrencilerin yabancı dile yönelik akademik başarılarında çeşitli bireysel değişkenlerin etkili olduğunu göstermektedir. Bu konuda Pishghadam ve Khajavy (2013) çalışmalarında, 
yabancı dil başarısında üstbiliş ve zekânın rolünü incelemişler ve her iki faktörün de katkıda bulunmasına rağmen üst bilişin yabancı dil başarısının bir yordayıcısı olarak zekâdan daha ağır bastığını bulmuşlardır. İnal, Evin Gencel ve Saracaloğlu'nun (2005) çalışmasında yabancı dil tutumu ile akademik başarı arasında anlamlı bir ilişki olduğu tespit edilmiştir. Öğrenme stilleri ile yabancı dil başarısı arasındaki ilişkinin üniversite düzeyinde incelendiği başka bir çalışmada, yabancı dil derslerinde başarılı olan öğrencilerin samimi sınıf tasarımlarını sevme ve kinestetik stili tercih etmeme eğiliminde oldukları ortaya konulmuştur (Bailey, Onwuegbuzie ve Daley, 2000). Şeker'in (2015) çalışmasında öz yönlendirmeli öğrenmenin yabancı dil başarısının önemli bir yordayıcısı olduğu tespit edilmişken, Onwuegbuzie, Bailey ve Daley (2000)'nin çalışmalarında bilişsel, duyuşsal, kişilik ve demografik değişkenlerin hepsinin sırasıyla bilişsel ve duyuşsal yordayıcılar başta olmak üzere yabancı dil başarısı ile ilişkili olduğu belirlenmiştir. Yabancı dili, o dilin konuşulduğu kültür bağlammda ele alan Gardner (1985) ise dil öğrenirken o dilin konuşulduğu topluma karşı olumlu bir tutumun gerekliliğine işaret etmiştir.

Öğrencilerin yaratıcılıkları ile yabancı dil başarıları arasında anlamlı bir ilişki olduğunu gösteren çalışmaların yanı sıra (Otto, 1998; Pishghadam, Khodadady ve Zabihi, 2011), söz konusu alandaki yeterliği kaygı (Batumlu ve Erden, 2007; Dalkılıç, 2001; Gardner, Moorcroft ve MacIntyre, 1987; Hewitt ve Stephenson, 2012; Horwitz. 2001; Onwuegbuzie, Bailey ve Daley, 1999), motivasyon (Amjadiparvar ve Zarrin, 2019; Binalet ve Guerra, 2014; Dörnyei, 1990; Gardner, 1985; Khodadady ve Khajavy, 2013), dil öğrenme stratejilerinin kullanımı (Fewell, 2010; Habók ve Magyar, 2018; Tabatabaeia ve Mashayekhi, 2013; Uslu, Şahin ve Odemis, 2016; Wong ve Nunan, 2011) gibi çeşitli değişkenler açısından ele alan pek çok araştırmaya rastlamak mümkündür.

Yukarıda bahsi geçen değişkenler arasından duyuşsal özelliklerin önemini vurgulayan Chastain'e (1988) göre, dil öğrenmede zihinsel olarak hazır olabilmenin önşartı duyuşsal hazırlıktır (Akt; Karakış, 2014). İlgi, tutum, güdülenmişlik, öz-yeterlik, kaygı, benlik, kişilik, değer yargıları gibi boyutları içeren duyuşsal özellikler öğrenme ortamında bireyin başarısını önemli ölçüde etkilemesine karşın sıklıkla ihmal edilmektedir (Cerit Berber ve Sarı, 2010; Gömleksiz, 2003; Gömleksiz ve Ülkü Kan, 2012; Reece ve Walker, 1997).

Dil öğrenimini duyuşsal boyutu ile ele alan Mills, Pajares, ve Herron'a (2006) göre, bir öğrenci bir dilde ne kadar rahat hissederse o dilde o kadar 
etkin olacaktır. Bununla birlikte, Price (1991) dil öğrenme ortamının kayg1 oluşturmaya oldukça elverişli olduğunu iddia etmiştir. Öğrenciler için yabancı dil dersleri, kendilerini yetersiz hissettikleri ve çok az pratik yaptıkları bir dilde iletişim kurmaktan rahatsız oldukları için endişe verici bir ortam olabilir (Moreno ve Kilpatrick, 2018). Bunun yanı sıra, dil öğrenmeye yönelik olumsuz deneyimler öğrencide dil öğrenme konusunda belirli yeteneklerin olması gerektiği, ancak kendisinin söz konusu yeteneklerden yoksun olduğu algısına yol açabilir (Horwitz, 1988). Birçok öğrenci yabancı dil derslerinde kendi yeterliklerine ilişkin inanca sahip olmadıkları için sınıfta kaybolmuş hissedebilirler (Oxford ve Shearin, 1994). Kendi yapabilirliklerine yeterince inancı olmayan öğrenciler yeni bir şey öğrenmek için çaba göstermeyi de gereksiz görerek zorluklar karşısında kolayca pes edebilirler (Kotaman, 2008). Nitekim Bandura (1993) başarıda sadece beceri sahibi olmanın yeterli olmayıp bu becerileri etkili kullanma konusunda özyeterlik inancının da gerekli olduğunu vurgulamış ve bireyin özyeterlik düşüncesindeki dalgalanmaların zayıf, yeterli veya olağanüstü performanslara yol açabileceğini öne sürmüştür. Dolayısıyla bu noktada, öğrencilerin yaptıkları seçimleri ve izledikleri eylem yollarını etkileyen ve başarılarına katkıda bulunan önemli bir faktör olarak özyeterlik (Pajares, 2002) kavramı karşımıza çıkmaktadır.

Alanyazında, özyeterlik algısı ya da özyeterlik inancı olarak geçen bu kavram ilk olarak Bandura'nın Sosyal Bilişsel Öğrenme Kuramında ortaya çımıştır. Bandura (1982, s. 122) özyeterlik kavramını, olası durumlarla başa çıkmak için gereken eylem yollarını ne kadar iyi yürütebileceğine dair kişisel bir yargı olarak tanımlarken, Bernhardt (1997) için bu kavram, öğrencilerin yetenekleri hakkındaki inançlarıdır. Bandura (1977; 1986) kişilerin özyeterlik inançlarının gelişimi üzerinde en etkili olan kaynağın başarılı deneyimler olduğunu ileri sürmüştür. Zira bir görevle ilgili tekrar eden başarılar, kişinin o göreve ilişkin özyeterlik inancının artmasını sağlarken, söz konusu görevle ilgili başarısızlıklar, o görevle ilgili özyeterliği güçsüzleştirmektedir. Bununla birlikte, Dörnyei (1994) güçlü bir şekilde oluşturulmuş özyeterlik algısı sayesinde öğrenme ortamında yaşanan bazı başarısızlıkların çok fazla olumsuz etkisinin olmayacağını savunmuştur.

Özyeterlik, bireyin beceri, kapasite ya da potansiyelinde ne kadar yetkin olduğu ile değil, bunlara ilişkin inancı ile ilgili bir kavramdır (Kotaman, 2008; Woolfolk, 2001). Konu ile ilgili olarak Bandura (1989), bir beceriye sahip olmakla, o beceriyi değişik koşullar altında etkin ve tutarlı şekilde kullanmanın 
aynı şey olmadığını ileri sürmüş̧ür. Belli bir görevle ilgili kişi, yeterli bilgiye, beceriye ve kabiliyete sahip olsa bile, bunların yeterince farkında olmayabilir veya sahip olduğundan daha çok ya da daha az kapasiteye ya da potansiyele sahip olduğuna inanabilir. Bu algı nedeniyle kişi, göreve ilişkin davranışa başlamaya bile yeltenmeyerek gerekli çabayı göstermeyebilir. Diğer taraftan, yüksek özyeterlik algısına sahip bireyler başarısız olma konusunda daha az korku duyarak başarısızlık durumlarında bile çabalarını sürdürmeye devam ederler (Genç, Kuluşaklı ve Aydın, 2016; Pajares ve Schunk, 2001; Woolfolk, 2001). Başka bir deyişle, bireyin özyeterliğine olan inancı ne kadar güçlü olursa, çabaları da o kadar büyük ve kalıcı olacaktır (Bandura, 1989). Buna karşın, düşük özyeterlik inancı daha az çabaya yol açarak daha düşük başariya neden olacaktır (Lorsbach ve Jinks, 1999). Oysa öğrenme çaba gerektiren bir süreçtir ve bu durum zaman ve emek gerektiren ve zorlu bir süreç olan yabancı dil öğrenimi için de geçerlidir.

Çaba eğitim sürecinde harcanan toplam enerji miktarını ifade eder (Zimmerman ve Risenberg, 1997). Bozick ve Dempsey (2010) öğrenme çabasını öğrencilerin bir beceriye hakim olmaları veya bir görevi tamamlamaları için meşgul oldukları davranışlar dizisi olarak tanımlamış ve yöntemsel/biçimsel çaba (procedural), devamlı çaba (substantive) ve uymama olmak üzere üç kategoriye ayırmışlardır. Yöntemsel/Biçimsel çaba, dakik olma, sınıf içinde dikkatli ve hazır olma, ödevleri yapma gibi minimum gayret gerektiren, görev tamamlama ve okul ve sınıf kurallarına uyma davranışlarını içermektedir. Devamlı çaba, öğrenmeye aktif katılımı ifade etmektedir. Okulda çok çalışmak, sınavlara hazırlanmak veya ders çalışmak için fazladan zaman ayırmak gibi öğrenme davranışları devamlı çabaya örnek olarak gösterilebilir. Uymama ise, sınıfta uygunsuz davranışlar sergileme, hayal kurma, derse geç gelme veya verilen ödevi tamamlamama gibi öğrenmeyi engelleyen davranışları kapsamaktadır.

Başka bir çalışmada, çaba öğrencilerin öğretmenleri ve/veya okulları tarafından belirlenen resmi akademik gereklilikleri karşılamak için harcadıkları zaman ve enerji miktarı olarak tanımlanmış ve kural odaklı (rule-oriented), yöntemsel/biçimsel (procedural) ve zihinsel (intellectual) olmak üzere üç farklı türünden söz edilmiştir (Carbonaro, 2005). Kural odaklı çaba, öğrencilerin düzenli olarak sınıfa gelme ve uygunsuz davranışlardan kaçınma gibi, okulun gerektirdiği en temel kural ve normlara uymasını gerektirirken; yöntemsel/biçimsel çaba, ödevleri tamamlama ve zamanında teslim etme ve sınıf 
tartışmalarına katılma gibi öğretmenin belirli taleplerini karşılama çalışmalarını içermektedir. Zihinsel çaba ise, öğrencinin ders içeriğini anlama ve bu içeriğe hakim olma yolundaki kararlılığını içerir (Carbonaro, 2005). Karabıyık ve Mirici (2018) ise öğrenme çabasını yabancı dil bağlamında ele alarak bu kavramı öğrencilerin yabancı bir dili öğrenme eylemine yatırdıkları bireysel kaynak miktarı olarak tanımlanmış ve yabancı dil öğrenme sürecini tamamlamak için öğrencilerin harcadıkları sınıf içi ve sınıf dışı emeklerle karakterize edildiğini ileri sürmüşlerdir.

Bandura (1989) insanların çabalarıyla kendilerindeki ve durumlarındaki değişimi etkileyebileceklerini iddia etmiştir. Dörnyei (2001) ise başarıyı kolaylaştırması ve herkese eşit şans vermesi açısından çabanın rolünü vurgulamıştır. Nitekim alanyazında çaba ve başarı arasında olumlu bir ilişkinin olduğunu ortaya koyan bazı araştırmalar bu görüşü destekler niteliktedir (Özer, 2020; Twum Ampofo ve Osei-Owusu, 2015; Carbonaro, 2005; Opare ve Dramanu, 2002; Phan, 2008; Stewart, 2008). Siegle ve McCoach'a (2007) göre, öğrenciler akademik başarılarını çaba ile ilişkilendirdiklerinde veya başarılarını çabaya bağlayan geri bildirim aldıklarında, gelecekteki beceri gelişimi için daha yüksek bir özyeterlik ve beklenti geliştirirler. Özyeterlik ise en önemli başarı yordayıcıları arasında yer almaktadır (Bandura, 1997; Zimmerman, Bandura ve Martinez-Pons, 1992). Bu bilgiler doğrultusunda, gerek özyeterlik inancının gerekse de çabanın öğrenci başarısını etkileyen ve ondan etkilenen değişkenler olduğunu söylemek mümkündür.

Dil öğrenimi/öğretimi alanında, özyeterlik ve başarı veya dil öğrenme çabası ve başarı arasındaki ilişkiye yönelik giderek artan bir ilgi söz konusu olsa da (Aratibel, 2013; Carbonaro, 2005; Ghonsooly ve Elahi, 2011; Inagaki, 2014; Kitikanan ve Sasimonton, 2017; Ma Guang-hui, 2005; Shah ve Ng, 2005; Twum Ampofo ve Osei-Owusu, 2015) Türkiye alanyazınında İngilizce başarısını bahsi geçen değişkenler açısından ele alan çalışmalar oldukça kısıtlıdır (Başbay ve Gözüm, 2019; Kırmızı, 2015; Yalçın Tilfarlioğlu ve Çiftçi, 2011). Alanyazın taraması sonucunda, yabancı dil olarak İngilizce başarısı ve özyeterlik inancı arasındaki ilişkide dil öğrenme çabasının aracı rolünün ele alındığı herhangi bir araştırmaya rastlanılmamıştır. Bu nedenle, alanyazından edinilen bilgiler ışığında, İngilizce başarısını yordayabileceği düşünülen özyeterlik inancı ve dil öğrenme çabasının birlikte tek bir çalışmada yer alması bu çalışmanın çıkış noktasını oluşturmaktadır. Dolayısıyla bu çalışmanın İngilizce özyeterlik inancı ve dil öğrenme çabası ile İngilizce başarısı arasında 
bir ilişki olup olmadığına ve İngilizce özyeterlik inancının başarıya olan etkisinde dil öğrenme çabasının aracı rolüne açıklık getirerek alanyazındaki boşluğun doldurulmasına katkı sağlayacağı düşünülmektedir. Aynı zamanda, araştırma bulgularının konu ile ilgili çalışmalar yapan diğer araştırmacılara, öğretmenlere, öğretim elemanlarına İngilizce başarısı ile ilişkisi olan değişkenler hakkında veri sunması ve başarıyı artıııı düzenlemeler yapmalarına yardımcı olacak fikirler verecek olması bakımından önemli olduğu düşünülmektedir. Bu doğrultuda, çalışmanın amacı, öğretmen adaylarının İngilizce özyeterlik inançlarının algılanan başarıları üzerindeki etkisinde dil öğrenme çabasının aracı rolünü incelemektir. Bu amaç doğrultusunda araştırma sorusu aşağıdaki şekilde belirlenmiştir:

1. Öğretmen adaylarının İngilizce öz-yeterlik inançlarının algılanan başarıları üzerindeki etkisinde dil öğrenme çabasının aracı rolü var mıdır?

\section{Yöntem}

\section{Araştırmanın Modeli}

Araştırmada bağımsız değişkenlerin bağımlı değişken üzerindeki yordayıcı gücünü ortaya koymak amacıyla nicel araştırma yöntemlerinden ilişkisel tarama modeli kullanılmıştır. Çalışmada, İngilizce özyeterlik inancı bağımsız değişken ve algılanan başarı bağımlı değişken iken yabancı dil öğrenme çabası aracı değişkendir. Değişkenler arasındaki ilişkiler hakkında daha ayrıntılı bilgiler elde etmek için ilişkisel tarama yöntemi kullanılmıştır (Cresswell, 2009).

\section{Evren ve Örneklem}

Araştırmanın evrenini, 2018-2019 bahar yarıyılında bir devlet üniversitesinin eğitim fakültesinde zorunlu Yabancı Dil II dersini alan 415 öğretmen adayı oluşturmaktadır. Örneklem $\mathrm{n}=\frac{N \cdot z^{2} \cdot p \cdot q}{N \cdot d^{2}+Z^{2} \cdot p \cdot q}$ formülü kullanılarak hesaplanmıştır (Yamane, 2006). Formülde,

$\mathrm{N}$ : Evrendeki birey sayısını,

n: Örneklemde yer alacak birey sayısını,

z: İstenilen güvenirlik düzeyi için standart normal dağılım tablo değerini,

d: Duyarlılığ 1 ve

$\mathrm{p}$ : Evrende istenilen özelliği taşıyan bireylerin oranını $(\mathrm{p}+\mathrm{q}=1)$ ifade etmektedir. 
Formülde değerler yerine koyulduğunda, çalışmanın örneklem büyüklügü 182 olarak hesaplanmıştır. Bu çalışmaya gönüllü olarak 256 öğretmen adayı katılmıştır, dolayısıyla bu sayı örneklem büyüklüğü açısından yeterli görülmüştür (Yamane, 2006). Örneklem grubunun özellikleri Tablo 1'de verilmiştir.

Tablo 1. Örneklem Grubunun Özellikleri

\begin{tabular}{|c|c|c|c|}
\hline Özellikler & & f & $\%$ \\
\hline \multirow[t]{2}{*}{ Cinsiyet } & Kadın & 188 & 73.4 \\
\hline & Erkek & 68 & 26.6 \\
\hline \multirow{9}{*}{ Yaş } & 18 & 49 & 19.1 \\
\hline & 19 & 87 & 34 \\
\hline & 20 & 83 & 32.4 \\
\hline & 21 & 25 & 9.8 \\
\hline & 22 & 7 & 2.7 \\
\hline & 23 & 2 & .8 \\
\hline & 24 & 1 & .4 \\
\hline & 25 & 1 & .4 \\
\hline & 28 & 1 & .4 \\
\hline \multirow{9}{*}{ Bölüm } & Fen Bilgisi Öğretmenliği & 40 & 15.6 \\
\hline & Beden Eğitimi ve Spor Öğretmenliği & 35 & 13.7 \\
\hline & Rehberlik ve Psikolojik Danışmanlık Öğretmenliği & 35 & 13.7 \\
\hline & Sınıf Öğretmenliği & 33 & 12.9 \\
\hline & Okul Öncesi Öğretmenliği & 31 & 12.1 \\
\hline & Özel Eğitim Öğretmenliği & 28 & 10.9 \\
\hline & Sosyal Bilgiler Öğretmenliği & 21 & 8.2 \\
\hline & Türkçe Öğretmenliği & 20 & 7.8 \\
\hline & İlköğretim Matematik Öğretmenliği & 13 & 5.1 \\
\hline \multirow{5}{*}{ Algılanan Başarı } & 5 (En yüksek) & 8 & 3.9 \\
\hline & 4 & 64 & 21.9 \\
\hline & 3 & 120 & 40.6 \\
\hline & 2 & 53 & 24.2 \\
\hline & 1 (En düşük) & 11 & 9.4 \\
\hline Toplam & & 256 & 100 \\
\hline
\end{tabular}

Tablo 1'de görüldüğü gibi, örneklem grubunda yer alan 256 öğretmen adayından 188'i (\%73.4) kadın, 68'i (\%26.6) erkektir. Öğretmen adaylarının yaşları 18 ile 28 arasında değişmekte olup yaşlarının ortalaması 19.5'tir. Öğretmen adaylarının 40' 1 (\%15.6) Fen Bilgisi Öğretmenliği, 35'i (\%13.7) Beden Eğitimi ve Spor Öğretmenliği, 35'i (\%13.7) Rehberlik ve Psikolojik Danışmanlık Öğretmenliği, 33'ü (\% 12.9) Sınıf Öğretmenliğii, 31'i (\%12.1) Okul Öncesi Öğretmenliği, 28'i (\%10.9) Özel Eğitim Öğretmenliği, 21'i (\%8.2) Sosyal Bilgiler Öğretmenliği, 20'si (\%7.8) Türkçe Öğretmenliği ve 13'ü (\%5.1) İlköğretim 
Matematik Öğretmenliği bölümlerinde öğrenim görmektedir. 11 öğretmen adayı İngilizce dersindeki başarısını 1, 53 öğretmen adayı 2, 120 öğretmen adayı 3, 64 öğretmen adayı 4 ve sadece 8 öğretmen adayı 5 olarak algılamaktadir.

\section{Veri Toplama Araçları}

Bu çalışmanın amacı, öğretmen adaylarının İngilizce özyeterlik inancının algılanan başarıları üzerindeki etkisinde dil öğrenme çabasının aracı rolünü incelemektir. Bu nedenle, çalışmada veriler özyeterlik inancı ölçeği ve dil öğrenme çabası ölçeği kullanarak toplanmıştır. Ayrıca öğretmen adayları kendi algılarını yansıtan başarı düzeylerini belirtmişlerdir. Bu bölümde, veri toplama araçlarına ait ayrıntılı bilgilere yer verilmiştir.

Özyeterlik inancı ölçeği: Araştırmada Yanar ve Bümen (2012) tarafından geliştirilen "İngilizce ile ilgili Özyeterlik İnanc Ölçeği” kullanılmıştır. Ölçek, okuma, yazma, dinleme ve konuşma olmak üzere dört boyut ve toplam 34 maddeden oluşmaktadır. Ölçekte maddeler "Bana tamamen uyuyor", "Oldukça uyuyor", "Biraz uyuyor", "Çok az uyuyor" ve "Bana hiç uymuyor" olarak derecelendirilmiştir. Yanar ve Bümen (2012) tarafından geliştirilen ölçek lise öğrencileri ile geliştirildiği ve bu araştırmanın evrenini öğretmen adayları oluşturduğu için, ölçek bu çalışmada doğrulayıcı faktör analizi ile yeniden analiz edilmiştir. Analizlerden sonra okuma boyutundan üç madde (2., 3. ve 4. maddeler), yazma boyutundan iki madde (9. ve 18. maddeler), dinleme boyutundan bir madde (28. madde) ve konuşma boyutundan bir madde (34. madde) çıkarılmıştır. Yedi madde çıkarıldıktan sonra modelin uyum indekslerinin $\left(\chi^{2}=579.555, \mathrm{df}=315, \chi 2 / \mathrm{df}=1.840, \mathrm{GFI}=.86, \mathrm{NFI}=.90\right.$, $\mathrm{IFI}=.95, \mathrm{CFI}=.95, \mathrm{RMSEA}=.06$ ) iyi ve kabul edilebilir düzeyde olduğu anlaşılmıştır. Bu çalışmada, Cronbach alfa katsayılarının okuma boyutu için .88, yazma boyutu için .92 , dinleme boyutu için .94 , konuşma boyutu için .90 ve ölçeğin tamamı için .97 olduğu tespit edilmiştir.

Dil öğrenme çabası ölçeği: Araştırmada Karabıyık ve Mirici (2018) tarafından geliştirilen "Yabancı Dil Öğrenme Çabası Ölçeği” kullanılmıştır. Ölçek uymama, yöntemsel/biçimsel çaba, devamlı çaba ve odaksal çaba olarak dört boyut ve 17 maddeden oluşmaktadır. Ölçekte maddeler "Hiçbir zaman", 
"Nadiren", Bazen", Sık sık" ve "Her zaman" olarak derecelendirilmiştir. Karabıyık ve Mirici (2018) tarafından geliştirilen ölçek Yabancı Diller Yüksekokullarında hazırlık sınıflarında öğrenim gören öğrenciler ile geliştirildiği ve bu araştırmanın evrenini öğretmen adayları oluşturduğu için, ölçek bu çalışmada doğrulayıcı faktör analizi ile yeniden analiz edilmiştir. Analizlerden sonra devamlı çaba boyutunda yer alan dört madde (1., 9., 11. ve 13. maddeler) ölçekten çıkarılmıştır. Dört maddenin çıkarılmasından sonra modelin uyum indekslerinin $\left(\chi^{2}=120.194, \mathrm{df}=59, \chi 2 / \mathrm{df}=2.037, \mathrm{GFI}=.93, \mathrm{NFI}=.89\right.$, $\mathrm{IFI}=.94, \mathrm{CFI}=.94, \mathrm{RMSEA}=.06)$ iyi ve kabul edilebilir düzeyde olduğu anlaşılmıştır. Bu çalışmada, Cronbach alfa katsayılarının uymama boyutu için .70, yöntemsel/biçimsel çaba boyutu için .75, devamlı çaba boyutu için .77, odaksal çaba boyutu için .79 ve ölçeğin tamamı için .78 olduğu tespit edilmiştir.

Algılanan başarı : Algılanan başarı, öğrencilerin devam ettikleri bir derse yönelik algıladıkları başarı seviyesini ifade eder. Algılanan başarı, öğrencilerin kendilerini çok sayıda öğrenme çıtısını kazanıp kazanmadıklarını değerlendirdiği bir yöntemdir ve maliyet etkin bir şekilde başarının alternatif bir ölçüsü olarak kullanılabilir (Ross, 2006). Alanyazındaki çalışmalar, öz değerlendirmenin öğrenme çıktılarını ölçmek için yararlı, güvenilir ve geçerli bir araç olduğunu göstermiştir (Ross, 2006). Özellikle yeterli öğrenme deneyimine sahip yetişkin öğrenciler algılanan başarıyı güvenilir bir şekilde ifade edebilirler (Kang, Yoon, Lim ve Yoo, 2012; Lim, Jin ve Kim, 2016). Alanyazında yer alan algilanan başarı ile ilgili çalışmaların (Ross, 2006; Lim vd. 2016; Kang vd., 2012) 1şığında ve bir program geliştirme uzmanının görüşü alınarak bu çalışmada, öğretmen adaylarından İngilizce dersindeki başarılarını 1 (en düşük) ile 5 (en yüksek) arasında puanlamaları istenmiş ve bu puanlar algılanan başarı olarak değerlendirilmiştir.

\section{Verilerin Analizi}

Veriler AMOS 19, SPSS 20 ve Hayes' (2013) PROCESS v. 2. 16.3 kullanılarak analiz edilmiştir. Araştırmada öncelikle verilerin normal dağılım gösterip göstermediği Kolmogorov Smirnov kullanılarak incelenmiştir. Özyeterlik inancı $(\mathrm{p}=.20>.05)$, dil öğrenme çabası $(\mathrm{p}=.09>.05)$ ve algılanan başarı $(p=.06>.05)$ ile ilgili verilerin normal dağılım gösterdiği tespit edilmiştir. Daha sonra, kullanılan her iki ölçeğin doğrulayıcı faktör analizleri için AMOS 19 ve 
korelasyon analizi için SPSS 20 kullanılmıştır. İngilizce özyeterlik inancı, dil öğrenme çabası ve algılanan başarı arasındaki ilişkiler, Pearson korelasyon analizi kullanılarak tespit edilmiştir. Verilerin regresyon analizi için gerekli varsayımları (Çokluk, Şekercioğlu ve Büyüköztürk, 2014; Büyüköztürk, 2011) karşıladığ sonucuna ulaşılmış ve İngilizce özyeterlik inancının algılanan başarı üzerindeki etkisinde dil öğrenme çabasının aracı rolünü belirlemek için 256 veri PROCESS Macro ile analiz edilmiştir. PROCES Macro, Hayes (2013) tarafından önerilen regresyon temelli aracılık analizlerini kapsamaktadır ve çalışmada Model 4 kullanılmıştır. Dil öğrenme çabasının dolaylı etkisini test etmek ve analizin istatistiksel gücünü arttırmak için Bootstraping güven aralikları (Bootstrapped confidence intervals) kullanılmıştır (Preacher, Rucker ve Hayes, 2007). Çalışmada, aracı değişkenin aracılık rolünün istatistiksel açıdan anlamlı olup olmadığı, \%95 güven aralığı (Bootstrap 95\% CI) ve 5000 Bootstrap örneklemi üzerinde incelenmiştir. Dolaylı etkinin anlamlı olabilmesi için, yanlılık hatasından arındırılmış ve düzeltilmiş düşük ve yüksek Bootstrapping güven aralığı sıfır içermemelidir (Hayes, 2013).

\section{Bulgular}

İngilizce özyeterlik inancı, dil öğrenme çabası ve algılanan başarı arasındaki ilişkileri belirlemek için Pearson korelasyon analizi uygulanmıştır. Bulgular Tablo 2' de verilmiştir.

Tablo 2. Çalışmada kullanılan değişkenlere ilişkin betimsel istatistikler ve korelasyon matrisleri

\begin{tabular}{llll}
\hline Değişkenler & İngilizce özyeterlik inancı & Dil öğrenme çabası & Algılanan başarı \\
\hline İngilizce özyeterlik inancı & 1.00 & & \\
\hline Dil ögrenme çabası & $.51^{*}$ & 1.00 & \\
\hline Algılanan başarı & $.67^{*}$ & $.46^{*}$ & 1.00 \\
\hline Ortalama & 2.63 & 2.83 & 2.87 \\
\hline SS & .80 & .51 & .81 \\
\hline Çarpıklık & .19 & -.52 & -.14 \\
\hline Basıklık & -.45 & .79 & -.20 \\
${ }^{* *} \times<.01$ & & &
\end{tabular}

Tablo 2'de görüldüğü gibi, İngilizce özyeterlik inancının ortalaması 2.63, dil öğrenme çabasının ortalaması 2.83 ve algılanan başarının ortalaması 2.87 'dir. İngilizce özyeterlik inancı ve dil öğrenme çabası arasında $(\mathrm{r}=.51$; $\mathrm{p}<.01)$, İngilizce özyeterlik inancı ve algılanan başarı arasında $(\mathrm{r}=.67 ; \mathrm{p}<.01)$ ve dil öğrenme çabası ile algılanan başarı arasında $(r=.46 ; \mathrm{p}<.01)$ anlamlı ve 
pozitif ilişkiler olduğu anlaşılmaktadır. Tüm korelasyon katsayılarının orta düzeyde olduğu anlaşılmıştır çünkü korelasyon katsayısı .30'un altında ise düşük, .30 ile .69 arasında ise orta ve .70'in üzerinde ise yüksek olarak değerlendirilmektedir (Çokluk, vd., 2014).

İngilizce özyeterlik inancının algılanan başarı üzerindeki etkisinde dil öğrenme çabasının olası aracı rolünü incelemek için PROCES Macro (Model 4) kullanılmıştır. Modelde yer alan yollar aşağıdaki gibidir:

Yol a = İngilizce özyeterlik inancı $\rightarrow$ Dil öğrenme çabası

Yol b= Dil öğrenme çabası $\rightarrow$ Algılanan başarı

Yol c= İngilizce özyeterlik inancı $\rightarrow$ Algılanan başarı

Yol c' $=$ İngilizce özyeterlik inancı $\rightarrow$ Dil öğrenme çabası $\rightarrow$ Algılanan başarı

Test edilen modeldeki dolaylı etki, 5000 Bootstrap örneklemi ile test edilmiştir. Tahminler \%95 güven aralığ 1 içinde değerlendirilmiş, yanlılık hatasından arındırılmış ve düzeltilmiş sonuçlar Tablo 3'te verilmiştir.

Tablo 3. Aracılık modeli, yol katsayılarn ve dolaylı etki testi

\begin{tabular}{|c|c|c|c|c|c|c|c|c|}
\hline & \multicolumn{6}{|l|}{ Yol } & \multicolumn{2}{|c|}{$\begin{array}{l}\text { Bootstrapping } \% 99 \\
\text { Güven Aralığı }\end{array}$} \\
\hline & $\beta$ & SH & $t$ & F & $\mathbf{R}$ & $\mathbf{R}^{2}$ & Düşük & Yüksek \\
\hline \multicolumn{9}{|c|}{ Model } \\
\hline Yol a & .33 & .03 & $9.45^{* *}$ & 89.31 & .51 & .26 & .26 & .40 \\
\hline Yol b & .27 & .09 & $3.10^{\prime \prime \prime}$ & 109.21 & .68 & .46 & .10 & .43 \\
\hline Yol c & .68 & .05 & $14.21^{*}$ & 201.95 & .67 & .44 & .59 & .77 \\
\hline Yol c ${ }^{\prime}$ & .09 & .03 & & & & & .04 & .15 \\
\hline
\end{tabular}

${ }^{* *} \mathrm{p}<.01$, Sobel $\mathrm{z}=2.93, \mathrm{p}=.003$.

Tablo 3'te, İngilizce özyeterlik inancının dil öğrenme çabası üzerinde anlamlı ve pozitif etkisi olduğu görülmektedir $(\beta=.33, t=9.45)$. Dil öğrenme çabasının algılanan başarı üzerinde anlamlı ve pozitif bir etkisi vardır $(\beta=.27$, $\mathrm{t}=3.10$ ). İngilizce özyeterlik inancının algılanan başarı üzerindeki doğrudan etkisi anlamlı ve pozitif bulunmuştur $(\beta=.68, \mathrm{t}=14.21)$. İngilizce özyeterlik inancı ve aracı değişken olan dil öğrenme çabası eş zamanlı olarak modele dahil edildiğinde, İngilizce özyeterlik inancının algılanan başarı üzerindeki etkisi azalmış $(\beta=.09)$ ancak anlamlılık değişmemiştir. Bootstrapping güven aralığında (\%95 CI) alt sınır .04 ve üst sınır .15 olarak bulunmuştur. \%95 Bootstrapping güven aralığı sıfır içermediğinden, aracılık etkisi .05 düzeyinde anlamlı kabul edilmiştir. Aracılık analizinden sonra modelin son hali Şekil 1'de sunulmuştur 


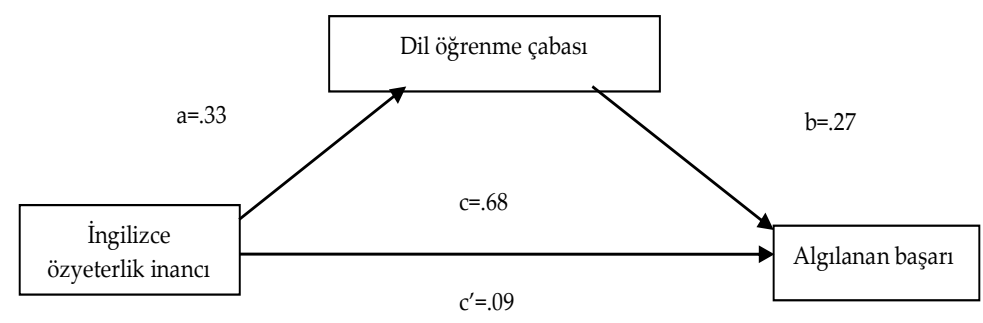

Şekil 1. İngilizce özyeterlik inancının algılanan başarı üzerindeki etkisinde dil öğrenme çabasının aracı rolï

Şekil 1'de görüldüğ̈̈ gibi, İngilizce özyeterlik inancı ve algılanan başarı arasındaki yolun (yol c) katsayı değeri yüksek ve anlamlıdır. Bununla birlikte, modele dil öğrenme çabası eklendiğinde, İngilizce özyeterlik inancı ve algılanan başarı arasındaki yolun (yol c') katsayı değeri azalmış, ancak anlamlılık değişmemiştir. İngilizce özyeterlik inancının dil öğrenme çabasının aracılığı ile algılanan başarı üzerindeki dolaylı etkisinin anlamlı olduğu bulunmuştur. Son olarak, Sobel testi ile katsayı değerindeki azalma anlamlı bulunmuştur ( $\mathrm{z}=2.93, \mathrm{p}<.01)$. Bu durumda, dil öğrenme çabası, İngilizce özyeterlik inancının algılanan başarı üzerindeki etkisinde aracı rol oynamıştır. Katsayıdaki azalmaya rağmen, etki hala anlamlı olduğundan, dil öğrenme çabasının İngilizce özyeterlik inancının algılanan başarı üzerindeki etkisine kısmen aracılık ettiği sonucuna varılmıştır.

\section{Tartışma ve Sonuç}

İngilizce özyeterlik inancının algılanan başarı üzerindeki etkisinde dil öğrenme çabasının aracı rolünün incelendiği bu araştırmada, öğretmen adaylarının İngilizce özyeterlik inançları, dil öğrenme çabaları ve algılanan başarıları arasında pozitif yönde orta düzeyde anlamlı bir ilişkinin olduğu ortaya çıkmıştır. Alanyazın incelendiğinde, bu çalışmanın sonucuna paralel şekilde, özyeterlik inancı ve başarı (Adeyemo, 2007; Hsieh ve Kang, 2010; Jackson, 2002; Meral, Çolak ve Zereyak, 2012; Peters, 2013; Tenaw, 2013; Uğraş, 2018; Yüksel ve Geban, 2016), çaba ve başarı (Bonesrønning ve Opstad, 2015; Carbonaro, 2005; Inagaki, 2014; Opare ve Dramanu, 2002; Shah ve Ng, 2005; 
Twum Ampofo ve Osei-Owusu, 2015) ve özyeterlik inancı ve çaba (Gao, Lodewyk ve Zhang, 2009; Li, 2012; Trevelyan, 2011) arasında anlamlı ilişkilerin olduğu görülmektedir.

Araştırmada ayrıca öğretmen adaylarının İngilizce özyeterlik inançlarının dil öğrenme çabalarını yordadığı belirlenmiştir. Yabancı bir dilde çalışmaya başlamada ve devam etmede özyeterlik inancının önemini vurgulayan Wen ve Johnson (1997), özyeterliği yüksek öğrencilerin düşük olan öğrencilere göre daha fazla bilişsel ve meta-bilişsel stratejiler kullandıklarını ve azimle çalışmaya devam ettiklerini öne sürmüşlerdir. Dolayısıyla özyeterlik inancı gösterilen çabayı etkileyebilmektedir (Awang-Hashim, O’Neil ve Hocevar, 2002). Özyeterlik inancı yüksek olan öğrencilerin daha fazla çaba harcamaları, zorlu görevleri seçmeleri ve bir görevde daha uzun süre devam etmeleri daha olası iken (Bandura, 1989; Schunk ve Zimmerman, 1997), düşük öz-yeterlik inancına sahip öğrencilerin daha az çaba harcamaları veya bir görevden tamamen uzaklaşmayı tercih etmeleri (Bandura, 1993; Pajares, 1996) muhtemeldir. Bu nedenden ötürü, Bandura (1997) özyeterlik inancının başarıyı bireyin gerçek yetenek seviyelerinden daha iyi yordayabileceğini savunmuştur.

Araştırmada dil öğrenme çabasının algılanan başarıyı yordadığı ortaya çıkmıştır. Bu sonuçla uyumlu olarak, yapılan bazı araştırmalar çabanın akademik performansın yordanmasına katkı sağladığını ortaya koymuştur (Bouffard, Boisvert, Vezeau ve Larouche, 1995; Opare ve Dramanu, 2002; Phan, 2008; Stewart 2008). Diğer yandan, başka bir çalışmada, çabanın akademik performansla anlamlı ve olumsuz bir şekilde ilişkili olduğu tespit edilmiştir (Chassie, O'Conner ve Walther, 2004). Bu durum çaba ve akademik başarı arasındaki ilişki konusunda genel bir fikir birliğine varmak için daha fazla araştırma yapılması gerektiğini düşündürmektedir. Çaba ile ilgili yapılan teorik ve deneysel araştırmaların yetersiz oluşunu Kuehn ve Landeras (2014) çabayı ölçmenin zorluğu ile ilişkilendirmişlerdir. Çabanın başarı ile olan ilişkisine yönelik olarak Dörnyei (2001), öğrencilerin daha fazla çaba göstermelerinin başarı olasılığı sunduğuna inanmaları sağlanabilirse, öğrenmeye eşlik eden başarısızlıklara rağmen çalışmaya devam edeceklerini ve başarı şanslarını eşitleyeceklerini iddia etmiştir. Benzer şekilde Littlewood (1999), doğuştan gelen yeteneklerin bir kişinin ulaşacağı başarıyı belirlemediğini, çaba ve öz-disiplinle herkesin hedeflerine ulaşabileceğini ve başarısızlığın daha fazla 
çaba gösterilerek giderilebileceğini öğrencilerin anlamasının sağlanması gerekliliğine işaret etmiştir.

İngilizce özyeterlik inancının algılanan başarının yordayıcısı olduğuna ilişkin ortaya çıkan araştırma sonucu, Cotterall'ın (1999) özyeterlik algısının dil öğrenenlerin başarısında önemli bir anahtar değişken olduğu görüşünü doğrulamaktadır. Bu sonuç, aynı zamanda Bandura'nın (1997) özyeterlik inancının diğer tüm değişkenlerden daha tutarlı bir davranış ve başarı yordayıcısı olduğu teorik görüşünü ve alanyazındaki özyeterlik inancının başarıyla olan ilişkisini açık bir şekilde ortaya koyan diğer çalışma bulgularını desteklemektedir (Kırmızı, 2015; Lent, Brown ve Larkin, 1986; Raoofi, Tan ve Chan, 2013; Skaalvik ve Skaalvik, 2006; Weiser ve Riggio, 2010). Başarı üzerindeki olumlu etkisinden dolayı öğrencilerde belirli bir göreve yönelik özyeterlik inancının geliştirilmesinin önemine değinen araştırmacılardan Dornyei ve Otto (1998), öğrencilerin izole bir şekilde var olmadıkların ifade ederek, özyeterlik inançlarının gelişimi üzerinde olumlu veya olumsuz etki yaratabilecek ebeveynler, akran grupları ve öğretmenler gibi bazı dış figürlere değinmişlerdir. Bu bağlamda, Cotterall (1999) ve Jabbarifar (2011), öğrencilerin dil öğrenmeye yönelik yetenekleri hakkındaki inançlarını keşfetme ve özyeterlik inançlarını destekleme ve geliştirmede yabancı dil eğitmenlerinin önemli rolleri olduğunun altını çizmişlerdir. Kotaman (2008) ve Bandura(1977; 1986) özyeterlik inancını artırmak için, izlenebilecek en etkili yolun öğrencilere bir konuda başarıyı tatmalarını sağlayacak alıştırmalar yaptırılmasını, o konu alanındaki gelişimleri ile ilgili açıklayıcı, doğru ve zamanında geribildirim sağlanmasını, öğrencileri çaba göstermeye, uygun ve verimli stratejiler kullanmaya teşvik edecek sınıf atmosferi oluşturulmasını önermişlerdir. Benzer bir şekilde, Çubukçu (2008) ve Oxford ve Shearin (1994) öğretmenlerin öğrencilere başarılı olabilecekleri ve üzerinde kontrol hissine sahip olabilecekleri anlamlı görevler vererek öğrencilerin özyeterlik inançlarını teşvik edebileceklerini ifade etmişlerdir. Moreno ve Kilpatrick (2018) ise, dil öğrenenlerin hedef dile ne kadar çok maruz kalırlarsa ve onunla etkileşime girerlerse, özyeterlik inançlarının o kadar fazla olacağı düşüncesinden hareketle yaptıkları uygulamada öğrencilerin özyeterlik inançlarının arttığını tespit etmişlerdir. Bahsi geçen çalışmada, özyeterlik inancını artırmak adına etkili bir yöntem olarak sınıfta topluluk dinamiği oluşturmak için program tasarımına daha fazla dikkat edilmesi önerilmiştir. Program geliştirme uzmanlarının sorumluluğunun 
vurgulandığı başka bir çalışmada (Demirel, 2004), yabancı dil eğitim programlarının öğrenci istekleri doğrultusunda şekillendirilmesi gerektiği vurgulanmıştır. Zira öğrencilerin özyeterlik inançlarını dikkate alan ve öğrenci odaklı bir dil programı tasarımı, dil öğrencilerinin yeteneklerine ilişkin olumlu inançlar geliştirmelerine yardımcı olabilir (Jabbarifar, 2011).

Araştırmada son olarak, dil öğrenme çabasının İngilizce özyeterlik inanc1nın algılanan başarı üzerindeki etkisine kısmen aracılık ettiği ortaya çıkmıştır. Buna göre, İngilizce özyeterlik inancı ile algılanan başarı arasındaki ilişkide dil öğrenme çabasının etkili olduğu ve algılanan başarıyı açıklamada dil öğrenme çabasının önemli rolü olduğu söylenebilir. Bu bulgu, çaba düzenlemesinin özyeterlik inancı ve genel not ortalaması arasındaki ilişkiye kısmen aracllık ettiğini ortaya koyan Komarraju ve Nadler'ın (2013) çalışma bulguları ile benzerlik göstermektedir.

$\mathrm{Bu}$ araştırmanın bazı sınırlı yönleri bulunmaktadır. Araştırmanın sınırlı yönlerinden birisi, Türkiye'nin İç Anadolu Bölgesi'nde bir devlet üniversitesinin eğitim fakültesinde gerçekleştirilmiş olmasıdır. Gelecek araştırmaların diğer bölgelerde, vakıf ve devlet üniversitelerinin bünyelerindeki farklı fakültelerde yürütülmesi daha farklı sonuçlar ortaya çıkarabilir. Bunun yanı sıra, ilkokul, ortaokul, lise kademelerine uygun olarak geliştirilecek anketlerle bu düzeylerde yapılacak benzer çalışmaların konunun daha büyük gruplarla ele alınması bakımından yararlı olacağı söylenebilir. Başarının algılanan başarı kapsamında ele alınmış olması araştırmanın bir başka sınırlılığı olarak değerlendirilebilir. Bu açıdan, gelecek araştırmalarda dil başarısının ölçülmesinde öğrencilerin not ortalamaları alınabilir ya da öğrencilere başarı testleri uygulanabilir. Ayrıca mevcut çalışma yabancı dil başarısı ile özyeterlik inancı ve dil öğrenme çabası arasında pozitif yönde anlamlı bir ilişki olduğunu doğruladığından dolayı, dil öğrenme çabası ve özyeterlik inancının kökenlerini ve bunlar üzerinde etkisi olabilecek çeşitli faktörleri belirlemeye veya öğrencilerin özyeterlik inançlarını ve dil öğrenme çabalarını arttırma yollarını araştırmaya odaklanan çalışmaların yapılması önerilebilir. Gelecekte yapılacak araştırmalarda nitel ve nicel yöntemlerin bir arada kullanılmasının konunun daha derinlemesine ele alınması bakımından yararlı olacağı düşünülmektedir. 


\title{
EXTENDED ABSTRACT
}

\section{The Predictiveness of Prospective Teachers' English Self-Efficacy Beliefs on Their Perceived Success: The Mediating Role of Language Learning Effort}

\author{
Selda Özer - Fatma Başarır \\ Nevşehir Hacı Bektaş Veli University
}

The rapid and dizzying advances in the fields of transportation, communication, mass media and information technologies in recent years have brought along great social transformations and increasing international relations. Due to the reasons stated, societies have been engaged in activities that are increasingly overlapping and even exceeding the borders of countries. Competition resulting from these increasing international relations has rendered nations' inability to communicate in their mother tongue, thereby creating the need to learn the languages of other countries.

The exigency of learning a foreign language is obvious in this world, where borders have been lifted, competition has been accelerated and everyone can be reached instantly everywhere with communication tools. In this globalizing world, competence in at least one foreign language gain prominence in order to follow the developments and not to get lost in the rapid information circulation (Gömleksiz, 2002). It is also known that foreign language competence provides advantages to individuals such as getting and preserving a good job, being open to different cultures, gaining confidence with respect to traveling more comfortably, having a global understanding, improving social relationship and being an indicator of modernity (Memduhoğlu and Kozikoğlu, 2015; Özer and Korkmaz, 2016, Tekin Özel, 2019). Along with the effects of globalization and these advantages, foreign language learning/teaching has become an important field in Turkey. For this reason, foreign language courses take place as compulsory courses in curricula from the second grade of primary school up to higher education. However, it is observed that the desired proficiency level has not been achieved across the country in foreign language 
teaching/learning when compared to the effort, time and money spent (Aydın and Zengin, 2008; Genç, 2016; Memduhoğlu and Kozikoğlu, 2015).

Littlewood (2001) argued that the reflection of learners' individual differences on the language learning process was one of the factors which made foreign language learning complicated and problematic. In this context, it is possible to say that self-efficacy belief and effort are among these variables affecting foreign language success. Accordingly, the aim of the study is to analyze the mediating role of language learning effort on the effect of English self-efficacy belief on perceived success.

Correlational design was applied in the study in order to reveal the predictiveness of independent variables on the dependent variable. The participants of the research consisted of freshmen studying at a faculty of education at a state university in 2018-2019 spring semester. The data of the study were collected through Self-Efficacy Scale for English developed by Yanar and Bümen (2012) and Foreign Language Learning Effort Scale developed by Karabıyık and Mirici (2018). While Self-Efficacy Scale for English included 34 items with four factors as reading, writing, listening and speaking, Foreign Language Learning Effort Scale consisted of 17 items with four factors as non-compliance, procedural, substantial and focal. To measure perceived success, prospective teachers were asked to score their success in English between 1 (the lowest) and 5 (the highest). Data were analysed using AMOS 19, SPSS 20 and Hayes' (2013) PROCESS v. 2. 16.3. For confirmatory analyses of both scales, AMOS 19 was applied. SPSS 20 was applied for correlation analysis. The relationships among self-efficacy, learning effort and perceived success were measured using Pearson correlation analysis in SPSS 20. PROCESS macro was applied using 256 data to determine the mediating role of language learning effort in the predictiveness of self-efficacy on perceived success. Bootstrapped confidence intervals were used to test the indirect effect of language learning effort.

The findings of the research revealed that there was a significant positive relationship between English self-efficacy beliefs and language learning effort. There was a significant positive relationship between English self-efficacy beliefs and perceived success. In addition, the relationship between language learning effort and perceived success was significant and 
positive. It was determined that the participants' English self-efficacy beliefs predicted their language learning efforts. Another finding that emerged in the research was that language learning effort predicted perceived success. Similarly, it was found out that English self-efficacy beliefs predicted perceived success. Finally, the study revealed that language learning effort mediated the predictiveness of English self-efficacy beliefs on perceived success. Accordingly, it can be said that language learning effort is effective in the relationship between English self-efficacy belief and perceived success and it has an important role in explaining perceived success.

This study was carried out through scales with 256 prospective teachers studying at a state university in the Central Anatolia region of Turkey. Conducting similar research in other regions of Turkey, in different faculties within the body of foundation and state universities may yield different results. In addition, it can be said that similar studies to be carried out at primary, secondary and high schools will be beneficial in terms of addressing the issue with larger groups. In further research, it may be suggested to conduct studies which focus on determining the origins of effort and self-efficacy and various factors that may have impacts on effort and self-efficacy. Using qualitative and quantitative methods together in further studies will be beneficial in terms of handling the issue in-depth.

\section{Kaynakça / References}

Adeyemo, D. A. (2007). Moderating influence of emotional intelligence on the link between academic self-efficacy and achievement of university students. Psychology and Developing Societies, 19(2), 199-213.

Amjadiparvar, A. ve Zarrin, G. (2019). The relationship between EFL learners' level of language awareness and their motivation and achievement. The Journal of Language Learning and Teaching, 9(2), 37-48.

Aratibel, A. P. (2013). The effects of socio-economic background, personal effort, and motivation in English proficiency. Unpublished M.A. thesis, Universidad Publica de Navarra, Navarra, Spain.

Awang-Hashim, R., F. O'Neil, H. ve Hocevar, D. (2002). Ethnicity, effort, self-efficacy, worry, and statistics achievement in Malaysia: A construct validation of the state-trait motivation model, Educational Assessment, 8(4),341364, DOI: 10.1207/S15326977EA0804 3. 
Aydın, S. ve Zengin, B. (2008). Yabancı dil öğreniminde kaygı: Bir literatür özeti. Journal of Language and Linguistic Studies, 4(1), 81-94.

Bailey, P., Onwuegbuzie, A. J. ve Daley, C. E. (2000). Using learning style to predict foreign language achievement at the college level. System, 28, 115-133.

Bandura, A. (1977). Self-efficacy: Toward a unifying theory of behavioral change. Psychological Review, 84, 191-215.

Bandura, A. (1982). Self-efficacy mechanism in human agency. American Psychologist, 37(2), 122-147. DOI:10.1037/0003-066X.37.2.122.

Bandura, A. (1986). Social foundations of thought and action: A Social cognitive theory. Englewood Cliffs, NJ: Prentice-Hall, Inc.

Bandura, A. (1989). Human agency in social cognitive theory. American Psychologist, 44(9), 1175-1184.

Bandura, A. (1993). Perceived self-efficacy in cognitive development and functioning. Educational Psychologist, 28(2), 117-148.

Bandura, A. (1997). Self-efficacy: The exercise of control. New York: Freeman.

Başbay, A. ve Gözüm, E. (2019). Dil öğrenme stratejilerine göre İngilizce öz-yeterlik inancı ve İngilizce akademik başarıları. Dil Eğitimi ve Araştırmalan Dergisi, 5(1), 12-29.

Batumlu, D. Z. ve Erden, M. (2007). The relationship between foreign language anxiety and English achievement of Yildız Technical Unıversity School of foreign languages preparatory students, Journal of Theory and Practice in Education, 3(1), 2438.

Bernhardt, S. (1997). Self-efficacy and second language learning. The NCLRC Language Resource, 1(5).

Binalet, C. ve Guerra, J. (2014). A Study on the relationship between motivation and language learning achievement among tertiary students. International Journal of Applied Linguistics \& English Literature, 3(5), 251-260.

Bonesrønning, H. ve Opstad, L. (2015). Can student effort be manipulated? Does it matter?, Applied Economics, 47(15), 1511-1524, DOI: 10.1080/00036846.2014.997923.

Bouffard. T., Boisvert, J., Vezeau, C. ve Larouche, C. (1995). The impacts of goal orientation on self-regulation and performance among college students. British Journal of Educational Psychology, 65, 317-329.

Bozick, RN. ve Dempsey, T. ed. (2010). Effort. J. A. Rosen, E. J. Glennie, B. W. Dalton, J. M. Lennon ve R. N. Bozick, Noncognitive skills in the classroom: New perspectives on educational research içinde (s. 39-68). Research Triangle Park, NC: RTI International. 
Büyüköztürk, Ş. (2011). Sosyal bilimler için veri analizi el kitabı (15.Baskı). Ankara: Pegem Akademi.

Carbonaro, W. (2005). Tracking students' efforts and academic achievement. Sociology of Education, 78(1), 29-49.

Cerit Berber, N. ve Sarı, M. (2010). Kavramsal değişime dayalı öğretim stratejilerinin fizik dersine yönelik bazı duyuşsal özelliklerin gelişimine etkisi. Ahi Evran Üniversitesi Ĕ̈itim Fakültesi Dergisi, 11(2), 45-64.

Chassie, M.B., O'Conner, E.J. ve Walther, F. (2004). Expended effort and academic performance. Testing of Psychology, 7(4), 231-233.

Cotterall, S. (1999). Key variables in language learning: What do learners believe about them? System, 27(4), 493-513.

Creswell, J. W. (2009). Research design: Qualitative, quantitative, and mixed methods approaches (3rd Ed.). Thousand Oaks, CA: Sage.

Çokluk, Ö., Şekercioğlu, G. ve Büyüköztürk, Ş. (2014). Sosyal bilimler için çok değişkenli istatistik: SPSS ve LISREL uygulamalarn (3. Baskı). Ankara: Pegem Akademi.

Çubukçu, F. (2008). A study on the correlation between self-efficacy and foreign language learning anxiety. Journal of Theory and Practice in Education, 4(1), 148-158.

Dalkulıç, N. (2001). An investigation into the role of anxiety in second language learning. (Unpublished doctoral thesis). Çukurova University, Adana.

Demirel, Ö. (2004). Yabancı dil öğretimi. Ankara: Pegem A.

Dörnyei, Z. (1990). Conceptualising motivation in foreign-language learning. Language Learning, 40, 45-78.

Dörnyei, Z. (1994). Motivation and motivating in the foreign language classroom. Modern Language Journal, 78(3), 273-284.

Dörnyei, Z. (2001). Motivational strategies in the language classroom. Cambridge, MA:Cambridge University Press.

Dörnyei, Z. ve Otto, I. (1998). Motivation in action: A process model of L2 motivation. Working Papers in Applied Linguistics, 4, 43-69.

Elliot, A. (2007). A conceptual history of the achievement goal construct. A. Elliot ve C. Dweck(Eds.), Handbook of competence and motivation içinde(s.52-72). New York: Guilford Press.

Fewell, N. (2010). Language learning strategies and English language proficiency: An investigation of Japanese EFL university students. TESOL Journal, 2, 159-174.

Gao, Z., Lodewyk, K. ve Zhang, T. (2009). The role of ability beliefs and incentives in middle school students' intentions, cardiovascular fitness, and effort. Journal of Teaching in Physical Education, 28, 3-20. 
Gardner, R. C. (1985). Social psychology and second language learning: The role of attitudes and motivation. London: Edward Arnold.

Gardner, R. C., Moorcroft, R. ve MacIntyre, P.D. (1987). The role of anxiety in second language performance oflanguage dropouts (Research Bulletin No. 657) London: University of Western Ontario.

Genç, G. (2016). Attributions to success and failure in English language learning. The effects of gender, age and perceived success. European Journal of Educational Studies, 2(12), 25-43.

Genç, G., Kuluşaklı, E. ve Aydın, S. (2016). Exploring EFL learners' perceived self-efficacy and beliefs on English language learning. Australian Journal of Teacher Education, 41(2), 53-68.

Ghonsooly, B. ve Elahi, M. (2011). Learners' self-efficacy in reading and its relation to foreign language reading anxiety and reading achievement. Journal of English Language Teaching and Learning, 53(217), 45-67.

Gömleksiz, M. N. (2002). Üniversitelerde yürütülen yabancı dil derslerine ilişkin öğrenci görüşlerinin değerlendirilmesi: Furat Üniversitesi Örneği. Fırat Üniversitesi Sosyal Bilimler Dergisi, 12(1), 143-158.

Gömleksiz, M. N. (2003). İngilizce duyuşsal alana ilişkin bir tutum ölçeğinin geçerlik ve güvenirliği. Fırat Üniversitesi Sosyal Bilimler Dergisi, 13(1), 215-226.

Gömleksiz, M. N. ve Ülkü Kan, A. (2012). Eğitimde duyuşsal boyut ve duyuşsal öğrenme. Turkish Studies, 7(1), 1159-1177.

Habók, A., ve Magyar, A. (2018). The effect of language learning strategies on proficiency, attitudes and school achievement. Frontiers in Psychology, 8, 2358.

Hayes, A. F. (2013). Introduction to mediation, moderation and conditional process analysis: $A$ regression-based approach. Newyork, NY: The Guilford Press.

Hewitt, E. ve Stephenson, J. (2012). Foreign language anxiety and oral exam performance: A replication of Phillip's MLJ study. The Modern Language Journal, 96, 170-189.

Horwitz, E. K. (1988). The beliefs about language learning of beginning university foreign language students. The Modern Language Journal, 72(3), 283-294.

Horwitz, E. K. (2001). Language anxiety and achievement. Annual Review of Applied Linguistics, 21, 112-126.

Hsieh, P. P. H. veKang, H. S. (2010). Attribution and self-efficacy and their interrelationship in the Korean EFL context. Language Learning, 60(3), 606-627.

Inagaki, Y. (2014). A mediator between motives and learning effort: The role of acquisition goals in motivational process of foreign language learners. Proceeding of the Global Summit on Education GSE, Kuala Lumpur, Malaysia, 455-465. 
İnal, S., Evin Gencel, İ. ve Saracaloğlu, A. S. (2005). The Relation between Students Attitudes toward Foreign Language and Foreign Language Achievement. Language Journal, 130, 37-52.

Jabbarifar, T. (2011). The importance of self-efficacy and foreign language learning in the 21st century. Journal of International Education Research, 7(4), 117-126.

Jackson, W. J. (2002). Enhancing self-efficacy and learning performance. The Journal of Experimental Education, 70, 243-254.

Kang, M., Yoon, S., Lim, H. ve Yoo, Y. R. (2012). Identifying predicting power of metacognition, perceived interaction, presence on learning outcomes in web-based collaborative learning. Journal of Lifelong Learning Society, 8(2), 111-130.

Karabiylk, C. ve Mirici, İ. H. (2018). Development and validation of the foreign language learning effort scale for Turkish tertiary-level students. Educational Sciences: Theory and Practice, 18(2), 373-395.

Karakış, Ö. (2014). Lise öğrencilerinin İngilizce dersine yönelik kayguları, motivasyonları, özyeterlik algilarn ve Ingilizce ders başarlan arasundaki ilişki. Yayımlanmamış doktora tezi. Abant İzzet Baysal Üniversitesi, Bolu.

Khodadady, E. ve Khajavy, G. (2013). Exploring the role of anxiety and motivation in foreign language achievement: A structural equation modeling approach. Porta Linguarum, 20, 269-286.

Kırmızı, Ö. (2015). The interplay among academic self-concept, self-efficacy, selfregulation and academic achievement of higher education L2 learners. Journal of Higher Education and Science, 5(1), 32-40. DOI: 10.5961/jhes.2015.107.

Kitikanan, P. ve Sasimonton, P. (2017). The relationship between English self-efficacy and English learning achievement of L2 Thai learners. Language Education and Acquisition Research Network (LEARN) Journal, 10(1), 148-163.

Komarraju, M. ve Nadler, D. (2013). Self-efficacy and academic achievement: Why do implicit beliefs, goals, and effort regulation matter? Learning and Individual Differences, 25, 67-72. https://doi.org/10.1016/j.lindif.2013.01.005.

Kotaman, H. (2008). Özyeterlilik inanc ve öğrenme performansının geliştirilmesine ilişkin yazın taraması. Uludă̆ Üniversitesi Eğitim Fakültesi Dergisi, 21(1), 111-133.

Kuehn, Z. ve Landeras, P. (2014). The effect of family background on student effort. The B.E. Journal of Economic Analysis \& Policy, 14(4), 1337-1403.

Lent, R. W., Brown, S. D. ve Larkin, K. C. (1986). Self-efficacy in the prediction of academic performance and perceived career options. Journal of Counseling Psychology, 33(3), 265-269. https://doi.org/10.1037/0022-0167.33.3.265. 
Li, L. K. Y. (2012). A study of the attitude, self-efficacy, effort and academic achievement of cityu students towards research methods and statistics. Discovery - SS Student E-Journal, 1, 154-183.

Lim, K. Y., Jin, M. ve Kim, S. W. (2016). Relationships among self-determination, collaboration preference, cognitive and perceived achievement in flipped learning environment. Korean Association for Education Information and Media, 22(3), 439462.

Littlewood, W. (1999). Defining and developing autonomy in East Asian contexts. Applied Linguistics, 20(1), 71-94.

Littlewood, W. (2001). Foreign and second language learning; language acquisation research and its implications for the classroom. (15th Ed). Cambridge Univesity Press.

Lorsbach, A. W. ve Jinks, J. L. (1999). Self-efficacy theory and learning environment research. Learning Environments Research, 2, 157-167.

Ma, Guang-hui. (2005). The effects of motivation and effort on foreign language achievement. Journal of PLA University of Foreign Languages, 28(4), 37-41.

Memduhoğlu, H. B. ve Kozikoğlu, İ. (2015). Üniversite öğrencilerinin yabancı dil derslerine ilişkin tutumları. Dicle Üniversitesi Ziya Gökalp Eğitim Fakültesi Dergisi, 24, 184-202.

Meral, M., Çolak, E. ve Zereyak, E. (2012). The relationship between self-efficacy and academic performance. Procedia-Social and Behavioral Sciences, 46, 1143-1146.

Mills, N., Pajares, F. ve Herron, C. (2006). A reevaluation of the role of anxiety: Self-efficacy, anxiety, and their relation to reading and listening proficiency. Foreign Language Annals, 39(2), 276-295.

Moreno, R. ve Kilpatrick, J. (2018). Student perceptions of self-efficacy in the foreign language classroom: A design-based research study. EDeR - Educational Design Research, 2(1), 1-26. http://dx.doi.org/10.15460/eder.2.1.1214.

Onwuegbuzie, A. J., Bailey, P. ve Daley, C. E. (1999). Relationship between anxiety and achievement at three stages of learning a foreign language. Perceptual and Motor Skills, 88, 1085-93.

Onwuegbuzie, A. J., Bailey, P. ve Daley, C. E. (2000) Cognitive, affective, personality, and demographic predictors of foreign-language achievement, The Journal of Educational Research, 94(1), 3-15.

Opare, J. A. ve Dramanu, B. Y. (2002). Students' academic performance. Academic effort as an intervening variable. IFE PsychologIA: An International Journal, 10(2), 193-210.

Otto, I. (1998). The relationship between individual differences in learner creativity and language learning success. TESOL Quarterly, 32(4), 763-773. 
Oxford, R. ve Shearin, J. (1994). Language learning motivation: Expanding the theoretical framework.Modern Language Journal, 78(1), 1228. https://doi.org/10.2307/329249.

Özer, B. ve Korkmaz, C. (2016). Yabancı dil öğretiminde öğrenci başarısını etkileyen unsurlar. Ekev Akademi Dergisi, 67, 59-84.

Özer, S. (2020). Foreign language learning effort levels of students in English for Specific Purposes. Journal of Language and Linguistic Studies, 16(3), 1352-1367. Doi: 10.17263/jlls.803772

Pajares, F. (1996). Self-efficacy beliefs in academic settings. Review of Educational Research, $66,543-578$.

Pajares, F. (2002). Gender and perceived self-efficacy in self-regulated learning. Theory into Practice, 41(2), 116-125.

Pajares, F. veSchunk, D. H. (2001). Self-beliefs and school success: Self-efficacy, self-concept, and school achievement. R. Riding ve S. Rayner (Eds.), Selfperception içinde (s. 239-266). London: Ablex Publishing.

Peters, M. L. (2013). Examining the relationships among classroom climate, self-efficacy, and achievement in undergraduate mathematics: A multi-level analysis. International Journal of Science and Mathematics Education, 11(2), 459-480.

Phan, H. P. (2008). Exploring students' reflective thinking practice, processing strategies, efforts and achievement goal-orientation. Educational Psychology, 29(3), 297313.

Pishghadam, R. ve Khajavy, G. H. (2013). Intelligence and metacognition as predictors of foreign language achievement: A structural equation modeling approach. Learning and Individual Differences, 24, 176-181.

Pishghadam, R., Khodadady, E. ve Zabihi, R. (2011). Learner creativity in foreign language achievement. European Journal of Educational Studies, 3(3), 465-472.

Preacher, K. J., Rucker, D. D. ve Hayes, A. F. (2007) Addressing moderated mediation hypotheses: Theory, methods, and prescriptions. Multivariate Behavioral Research, 42(1), 185-227.

Price, M. L. (1991). The subjective experience of foreign language anxiety: Interview with highly anxious students. E. K. Horwitz, ve D. J. Young (Eds.), Language anxiety: From theory and research to classroom implications içinde (s. 101-108). Englewood Cliffs, NJ: Prentice Hall.

Raoofi, S., Tan, B. H. ve Chan, S. H. (2012). Self-efficacy in second language learning contexts. English Language Learning, 5(11), 60-73.

Reece, I. ve Walker, S. (1997). Teaching training and learning: A practical guide. Great Britain: Athenaeum Press. 
Ross, J. A. (2006). The reliability, validity, and utility of self-assessment. Practical Assessment Research \& Evaluation, 11(10), 1-13.

Schunk, D. H. ve Zimmerman, B. J. (1997). Social origins of self-regulatory competence. Educational Psychologist, 32, 195-208.

Shah, P. M. ve Ng, J. M. K. (2005). Acquisition of acrolect Malaysian English at an institution of higher learning. The International Journal of Learning, 12(5), 19-31.

Siegle, D. ve McCoach, D. B. (2007). Increasing student mathematics self- efficacy through teacher training. Journal of Advanced Academics, 18, 278-312.

Skaalvik, E. M. ve Skaalvik, S. (2006). Self-concept and self-efficacy in mathematics: Relation with mathematics motivation and achievement. In Prescott, A. P. (Ed.), The concept of self in education, family and sports (s. 51-74). New York, NY: Nova Science.

Stewart, E. B. (2008). School structural characteristics, student effort, peer associations, and parental involvement: the influence of school- and individual-level factors on academic achievement. Education and Urban Society, 40(2), 179-204.

Şeker, M. (2015). The use of self-regulation strategies by foreign language learners and its role in language achievement. Language Teaching Research, 20, 600-618.

Tabatabaei, O. ve Mashayekhi, S. (2013). The relationship between EFL learners' learning styles and their L2 achievement. Procedia-Social and Behavioral Sciences, 70, 245-253.

Tekin Özel, R. (2019). Yabancı dil öğretiminde yeni bir paradigma: Yöntem sonrası dönem. DTCF Dergisi, 59(2), 1057-1086.

Tenaw, Y. A. (2013). Relationship between self-efficacy, academic achievement and gender in analytical chemistry at Debre Markos college of the teacher education. African Journal of Chemical Education, 3(1), 3-28.

Trevelyan, R. (2011). Self-efficacy and effort in new venture development. Journal of Management \& Organization, 17(1), 2-16.

Twum Ampofo, E. T. ve Osei-Owusu, B. (2015). Students' academic performance as mediated by students' academic ambition and effort in the public senior high schools in Ashanti Mampong Municipality of Ghana. International Journal of Academic Research and Reflection, 3(5), 19-35.

Uğraş, M. (2018). Yedinci sınıföğrencilerinin motivasyon ile özyeterlik inançlarının Fen Bilimleri dersindeki başarılarıyla ilişkisinin incelenmesi. Bingöl Üniversitesi Sosyal Bilimler Enstitüsü Dergisi, 8(16), 495-508.

Uslu, M. E., Sahin, E. ve Odemis, I. S. (2016). The effect of language learning strategies on academic achievement. Journal of Educational and Instructional Studies in the World, 6(3), 73-78. 
Weiser, D.A. ve Riggio, H. R. (2010). Family background and academic achievement: Does self-efficacy mediate outcomes? Social Psychology Education, 13, 367-383. https://doi.org/10.1007/s11218-010-9115-1.

Wen, Q. ve Johnson, R. K. (1997). L2 learner variables and English achievement: A study of tertiary-level English majors in China. Applied Linguistics, 18(1), 24-48.

Wong, L. L. C. ve Nunan, D. (2011). The learning styles and strategies of effective language learners. System, 39(2), 144-163. Doi:10.1016/j.system.2011.05.004.

Woolfolk, A. E. (2001). Education psychology, 8th Edition, Allyn \& Bacon.

Yalçın Tilfarlioğlu, F. ve Çiftçi, F. Ş. (2011). Supporting self-efficacy and learner autonomy in relation to academic success in EFL classrooms (A case study). Theory and Practice in Language Studies, 1(10), 1284-1294. DOI: 10.4304/tpls.1.10.12841294.

Yamane, T. (2006). Temel örnekleme yöntemleri. A. Esin, C. Aydın, M. A. Bakır ve E. Gürbüzsel, Çev.. İstanbul: Literatür Yayınları.

Yanar, B.H. ve Bümen, N.T. (2012). İngilizce ile ilgili öz yeterlik inancı ölçeğinin geliştirilmesi. Kastamonu Ĕğitim Dergisi, 20(1), 97-110.

Yüksel, M. ve Geban, Ö. (2016). Examination of science and math course achievements of vocational high school students in the scope of self-efficacy and anxiety. Journal of Education and Training Studies, 4(1) 88-100.

Zimmerman, B. J. ve Risenberg, R. (1997). Self-regulatory dimensions of academic learning and motivation. G. Phye (Ed), Handbook of academic learning içinde (s. 105125). New York: Academic Press.

Zimmerman, B. J., Bandura, A. ve Martinez-Pons, M. (1992). Self-motivation for academic attainment: The role of self-efficacy beliefs and personal goal setting. American Educational Research Journal, 29(3), 663-676.

\section{Kaynakça Bilgisi / Citation Information}

Özer, S. ve Başarır, F. (2020). Öğretmen adaylarının İngilizce özyeterlik inançlarının algılanan başarıları üzerindeki etkisi: Dil öğrenme çabasının aracı rolü. OPUS-Uluslararası Toplum Araştırmaları Dergisi, 16(Eğitim ve Toplum Özel Sayıs1), 5704-5731. DOI: 10.26466/opus.771847 